\title{
PREGNANCY DETECTION IN RABBITS BY ULTRASONOGRAPHY AS COMPARED TO MANUAL PALPATION
}

\author{
M. El-Gayar ${ }^{1,2^{*}}$, H. Khalil ${ }^{1}$, A. Hanafy ${ }^{1}$, M. Yaseen $^{1}$, E. Hegaze ${ }^{1}$, D. Marthold ${ }^{2}$, M. Gauly ${ }^{2}$ and \\ W. Holtz ${ }^{2}$
}

${ }^{l}$ Department of Animal Production, Faculty of Agriculture, Suez Canal University, Ismailia, Egypt; ${ }^{2}$ Department of Animal Science, Georg-August-University, Goettingen, Germany

*Corresponding author: $\underline{\text { melgavar@yahoo.com }}$

\section{SUMMARY}

The most common way of detecting pregnancy in rabbits is by manual palpation. Real-time ultrasonography may be an alternative to be used in rabbit production units in the future if it turns out to be practicable. There is a paucity of scientific knowledge on the suitability of real-time ultrasonography for pregnancy diagnosis in rabbits. In the present study pregnancy diagnosis by transabdominal ultrasonography was compared to manual abdominal palpation in 28 mated New Zealand rabbit does. Ultrasonography with the aid of a real-time scanner, equipped with five $\mathrm{MHz}$ linear-array transducer and manual palpation were executed by one individual daily, beginning at day five after mating. For ultrasound scanning, does were restrained in a dorsal recumbent position and, to establish firm skin contact, gel was applied to the clipped caudal abdomen. Manual abdominal palpation provided a reliable diagnosis by day $10.9 \pm 0.3$. By ultrasonography, uterine fluid was detected $6.2 \pm 0.2$ days after mating; fetal heartbeat by day $7.8 \pm 0.1$. In the 20 does that went to term $(71 \%)$, the reliability of both ultrasonic pregnancy detection (based on the observation of heart beat) and manual palpation was $100 \%$. No abortions or stillborn kits were recorded and the kits born were normal and viable. In conclusion, real-time ultrasonography, being accurate, rapid and safe, may be considered as a viable alternative for other means of early pregnancy diagnosis in rabbits.

Keywords: rabbits, pregnancy diagnosis, ultrasonography, manual palpation

\section{INTRODUCTION}

Early identification of pregnancy is a key factor in decreasing the interval between successive inseminations, providing animals with appropriate diets and enable producers to identify unwilling or non-receptive does so they can be treated and/or remated in due time. The traditional way of pregnancy detection is by manual palpation of the abdomen (Hafez, 1970). The manual palpation provides fairly reliable results by day 10 to 14 of gestation (Hagen, 1974). Erroneous diagnoses may result from food or gas contents in the bowels. Heavy-handed palpation may harm fetuses and cause distress to the mother (Morrell, 1995). Real-time ultrasonography, available for pregnancy detection in various mammals since the early 1980s, may be successfully applied in rabbit does from day seven of gestation onward (Cubberley et al., 1982 and Inaba et al., 1986). The technique has been found to be useful to determine number as well as normal development or loss of fetuses (Inaba et al., 1986 and Ypsilantis and Saratsis, 1999).

The aim of the present study was to evaluate transabdominal ultrasonography as a mean of pregnancy detection and compare it with the manual abdominal palpation.

\section{MATERIALS AND METHODS}

The protocols involving the animals for this experiment were approved by of the Committee of
Environmental Affairs, Faculty of agriculture, Suez Canal University. At the rabbit facility of the Experimental Farm of the Faculty of Agriculture, Suez Canal University, Ismailia, Egypt a total of 56 pluriparous New Zealand white does, aged five to eight months and weighing $2.98 \pm 0.11 \mathrm{~kg}$, was housed in individual wire mesh cages and fed a balanced commercial diet (NRC, 1984) and water ad libitum. They were subjected to a 16 hour light photoperiod and mated to fertile bucks of the same strain. Does were mated during the same period of the day from 8:00 to 9:00 a.m. to prevent the influence of the time factor. The day of mating was considered day one of pregnancy. Does were allocated at random with reference to body weight to one of two groups. Does of group one were subjected to two different methods of pregnancy detection (manual abdominal palpation and trans-abdominal ultrasonography), those of Group two served as untreated controls.

Manual abdominal palpation was performed daily from five days after mating until conclusive establishment of pregnancy (at least two days in succession diagnosed positively pregnant). Ultrasonic exploration of the abdomen was conducted daily from five days after mating until conclusive establishment of pregnancy, using a real-time B-mode scanner equipped with a five $\mathrm{MHz}$ linear-array transducer (Honda HS-1500V, Honda Electronics, Japan). The does were gently restrained in a dorsal recumbent position and the shaved abdomen was explored from the pubis toward the sternum while moving the probe, 
covered with carboxymethyl-cellulose gel, to and fro in transverse direction in search for fluid-filled vesicles or fetal heartbeat (Figure 1). The time required, including restraint, clipping and examination, never exceeded seven minutes. All operations were executed by the same operator on the same time of the day (from 8 to $12 \mathrm{am}$ ). Control does were not subjected to pregnancy diagnoses.

Data were analyzed using a general linear model (GLM) procedure with the statistical analysis system (SPSS, 2009). Differences between means were tested by Duncan's new multiple test (Duncan, 1955).

\section{RESULTS AND DISCUSSION}

Out of the 28 does subjected to pregnancy diagnoses, $20(71 \%)$ gave birth 30 to 31 days after mating, as compared to $21(75 \%)$ of 28 in the control group. Litter size and kit weight at birth were similar for both groups (Table 1). Abdominal palpation provided a reliable diagnosis by day $10.9 \pm 0.3$. Realtime ultrasonography gave the first observation (uterine fluid) between days five and nine of gestation (average $=6.2 \pm 0.2$ ). Initially fluid-filled vesicles were recognizable as non-echogenic spherical structures. From day seven onward, fetuses were visible as areas of high echogenicity inside vesicles (Figure 1). Heart beat was also clearly discernible (day $7.8 \pm 0.1$ ). In does that went to term, the reliability of both manual palpation and ultrasonic pregnancy detection (based on the observation of heart beat) was $100 \%$ (Table 2).

Comparison of the two methods of pregnancy detection in rabbits confirms the suitability of manual abdominal palpation, the method most commonly applied. It calls for the least effort and requires no equipment. Given the required dexterity and skill this method is reliable from day 12 of pregnancy onward. If applied, heavy-handedly, however, may exert considerable strain to the doe and give rise to fetal loss (Morrell, 1995). Ultrasound scanning of the abdomen proved to be a safe and practical means of diagnosing pregnancy at an early stage. The time required, including restraint, clipping and examination, never exceeded seven minutes. Also, ultrasound scanning of the abdomen is helpful in diagnosis extrauterine pregnancy, ovarian tumours, abscesses, cysts, pyometra and hydrometra in rabbits (Varga, 2014).

The results show that pregnancy can be detected in does between days five and nine of gestation, which is as early as or earlier than reported in other similar studies (Ypsilantis and Saratsis, 1999). Fetal heartbeat, although occurring one to two days later than the accumulation of uterine fluid, is the more reliable indicator. Real-time ultrasonography, gave the first result as an accumulation of uterine fluid in rabbits, showing no fetal heartbeat will mean one of two things: either the pregnancy is too early along for the heartbeat to be visible, or a pregnancy loss has occurred. The echogenic approach requires suitable equipment and causes slightly more discomfort to the rabbits, yet it provides a reliable result as early as eight days after mating. It did not impair the wellbeing of does or number and weight of their kits. No abortions or stillborn kits were recorded.

Reproductive performance of both experimental groups (subjected vs. non-subjected to pregnancy diagnosis) is summarized in Table (1), and clearly indicates that none of the manipulations associated with pregnancy detection, such as abdominal palpation and sonication of does fixed in a supine position, interfered with maintenance of pregnancy or numbers and viability of offspring.

In conclusion, of the two methods for diagnosing pregnancy in rabbits, manual palpation calls for the least effort and requires no equipment. Yet, reliable results are only warranted from day 12 of pregnancy onward. Real-time ultrasonography provides accurate results as early as day eight after mating, providing that the suitable equipment and helping hands are available.

Table 1. Weight and reproductive performance of does

\begin{tabular}{lcc}
\hline Variable & Pregnancy tested does & Control does \\
\hline Number of does & 28 & 28 \\
Does pregnant $(\%)$ & $20(71 \%)$ & $21(75 \%)$ \\
Parity (Mean \pm SEM) & $2.3 \pm 0.3$ & $2.2 \pm 0.3$ \\
Body weight at mating (kg, Mean \pm SEM) & $2.97 \pm 0.13$ & $2.99 \pm 0.11$ \\
Body weight at parturition (kg, Mean \pm SEM) & $3.11 \pm 0.09$ & $3.17 \pm 0.18$ \\
Number of life kits at birth (Mean \pm SEM) & $6.9 \pm 0.6$ & $7.0 \pm 0.6$ \\
Weight / life kit $(\mathrm{g})$ at birth (Mean \pm SEM) & $56 \pm 2$ & $56 \pm 2$ \\
\hline
\end{tabular}

None of the differences between groups were significant ( $\mathrm{P}>0.05$, Duncan's new multiple test). 
Table 2. Reliability of positive $(n=20)$ and negative $(n=8)$ pregnancy diagnoses at different times after mating $(\%)$

\section{Days of pregnancy}

\begin{tabular}{lllllllllllll}
\cline { 2 - 4 } Method & 5 & 6 & 7 & 8 & 9 & 10 & 11 & 12 & 13 & 14 & 15
\end{tabular}

\begin{tabular}{|c|c|c|c|c|c|c|c|c|c|c|c|}
\hline \multicolumn{12}{|l|}{ Palpation } \\
\hline $\begin{array}{l}\text { Positive } \\
\text { (n) }\end{array}$ & $\begin{array}{l}100 \\
(0)\end{array}$ & $\begin{array}{l}100 \\
(0)\end{array}$ & $\begin{array}{l}100 \\
(0)\end{array}$ & $\begin{array}{l}100 \\
(0)\end{array}$ & $\begin{array}{l}100 \\
(3)\end{array}$ & $\begin{array}{l}100 \\
(9)\end{array}$ & $\begin{array}{l}100 \\
(10)\end{array}$ & $\begin{array}{l}100 \\
(20)\end{array}$ & -- & -- & -- \\
\hline $\begin{array}{l}\text { Negative } \\
\text { (n) }\end{array}$ & $\begin{array}{c}29 \\
(28)\end{array}$ & $\begin{array}{c}29 \\
(28)\end{array}$ & $\begin{array}{c}29 \\
(28)\end{array}$ & $\begin{array}{l}29 \\
(28)\end{array}$ & $\begin{array}{c}32 \\
(25)\end{array}$ & $\begin{array}{c}42 \\
(19)\end{array}$ & $\begin{array}{c}44 \\
(18)\end{array}$ & $\begin{array}{l}100 \\
(8)\end{array}$ & -- & -- & -- \\
\hline \multicolumn{12}{|l|}{ Ultrasound* } \\
\hline $\begin{array}{l}\text { Positive } \\
\text { (n) }\end{array}$ & $\begin{array}{l}100 \\
(0)\end{array}$ & $\begin{array}{l}100 \\
(0)\end{array}$ & $\begin{array}{l}100 \\
(5)\end{array}$ & $\begin{array}{l}100 \\
(19)\end{array}$ & $\begin{array}{l}100 \\
(20)\end{array}$ & -- & -- & -- & -- & -- & -- \\
\hline $\begin{array}{l}\text { Negative } \\
\text { (n) }\end{array}$ & $\begin{array}{c}29 \\
(28)\end{array}$ & $\begin{array}{c}29 \\
(28)\end{array}$ & $\begin{array}{c}35 \\
(23)\end{array}$ & $\begin{array}{l}89 \\
(9)\end{array}$ & $\begin{array}{c}100 \\
(8)\end{array}$ & -- & -- & -- & -- & -- & -- \\
\hline
\end{tabular}

*Based on the observation of heart beat.

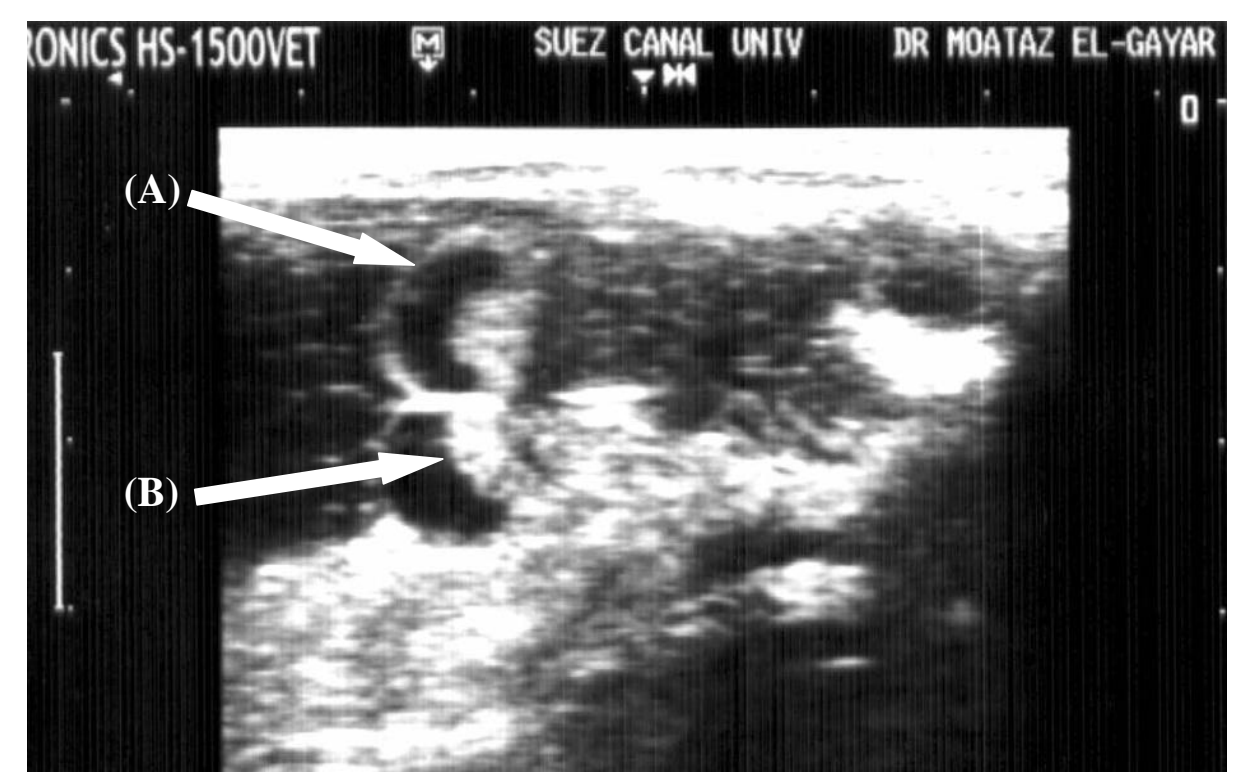

Figure 1. Ultrasound image of the uterus of a doe eight days pregnant. A: Fluid-filled vesicles visible as non-echogenic spaces. (B) A fetus

\section{REFERENCES}

Cubberley D.A., T.G. Lee and C.L. Laughlin, 1982. Importance of ultrasound determination of pregnancy in the rabbit. Am. J. Vet. Res., 43:1802-1803.

Duncan D., 1955. Multiple range and multiple F-test. Biometrics, 11: 1- 42.

Hafez E., 1970. Reproduction and Breeding techniques for Laboratory Animals, ed. E. S. E. Hafez, 273-298.

Hagen K., 1974. Colony husbandry. In: Weisbroth S.H., Flatt R.E., Kraus A.L. (eds). The biology of the laboratory rabbit. Academic Press. London, 23-49.
Inaba T., J. Mori and R. Torii, 1986. Use of echography in rabbits for pregnancy diagnosis. Japn. J. Vet. Sci., 48: 1003-1006.

Morrell J., 1995. Artificial insemination in rabbits. British Vet. J., 151: 477- 488.

NRC, 1984. National Research Council. Nutrient Requirements of Rabbits. The 2nd Revised Edition. National Academy of Science. Washington. D.C. USA.

SPSS, 2009. SPSS Version 18 for Windows. SPSS, Inc. USA.

Varga M., 2014. Urogenital Diseases, in Textbook of Rabbit Medicine, ed. M. Varga, 405-423.

Ypsilantis P. and P.H. Saratsis, 1999. Early pregnancy diagnosis in the rabbit by real time ultrasonography.World Rabbit Sci., 7 (2): 95-99. 


\section{تشخيص الحمل في الأرانب بإستخدام الموجات فوق الصوتية المصورة ومقارنتها بالجس البطني}

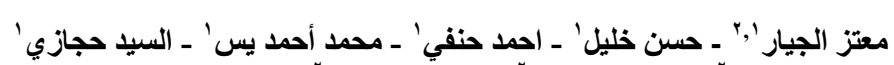

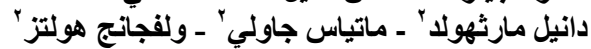

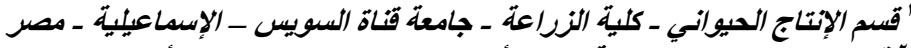

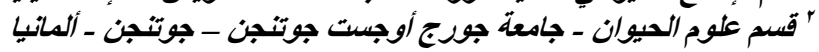

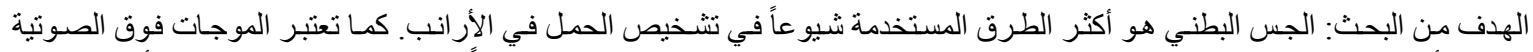

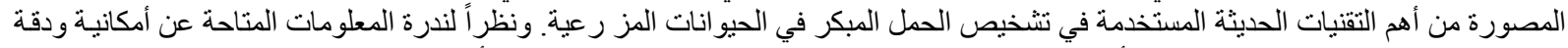

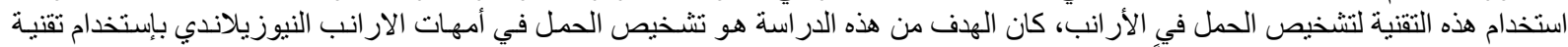

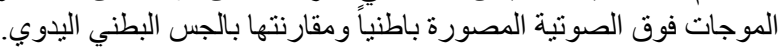

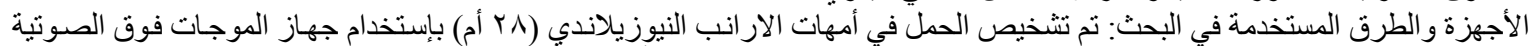

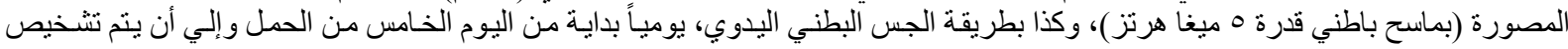
الحمل بشكل مؤكد.

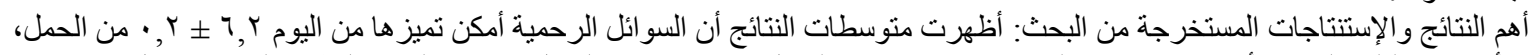

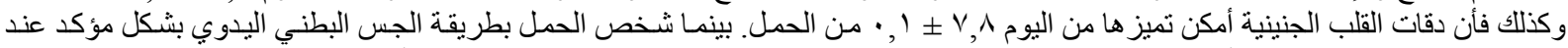

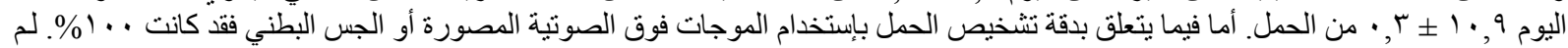

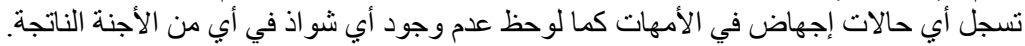

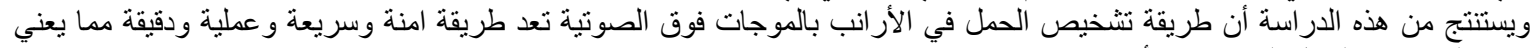
الوثوق فيها لتشخيص الحمل المبكر في الأرانب. 